\title{
Monitoreo genético en programas de repoblamiento de peces mediante marcadores moleculares
}

\author{
Jayme A. Povh ${ }^{1}$, Nelson M. Lopera Barrero, Ricardo P. Ribeiro, \\ Enio Lupchinski Jr., Patrícia C. Gomes y Taís S. Lopes \\ Departamento de Zootecnia, Programa de Pós-Graduação em Zootecnia, Universidade Estadual, \\ e Maringá, Grupo de Pesquisa PEIXEGEN, Av. Colombo, 5790, 87020-900, Maringá, PR, Brazil
}

\begin{abstract}
J.A. Povh, N.M. Lopera-Barrero, R.P. Ribeiro, E. Lupchinski Jr., P.C. Gomes, and T.S. Lopes. 2008. Genetic monitoring of fish repopulation programs using molecular markers. Cien. Inv. Agr. 35(1):5-15. Native fish populations are decreasing due to several impact factors of the environment. In order to address this problem, several actions, for example stocking, have been accomplished. However, if these actions are undertaken without any scientific support, their efficiency is low, and they can cause loss of genetic diversity in the populations, and irreversible impacts in the next generations. For this reason, the use of molecular markers to assess diversity through genetic monitoring, can contribute to the conservation of the icthyofauna.
\end{abstract}

Key words: Fish, genetic conservation, genetic variability, icthyofauna, microsatellite, RAPD.

\section{Introducción}

Brasil lidera la diversidad de peces de agua dulce con 2122 especies catalogadas, lo que corresponde a cerca del $21 \%$ de las especies del mundo (Buckup y Menezes, 2003). Más aún, se estima que 30 a $40 \%$ de la fauna de peces neotropicales de aguas continentales todavía no han sido descritas, por lo que un número más realista de peces para las aguas brasileñas puede ser de 5000 especies, pudiendo llegar hasta 8000 especies (Reis et al., 2003; Schaefer, 1998). Los peces neo-tropicales representan $13 \%$ de la biodiversidad total de los vertebrados, a pesar de que estén presentes en menos de 0,003\% (por volumen) de los ecosistemas acuáticos del mundo (Agostinho et al., 2005).

Se estima que $15 \%$ de toda la proteína animal consumida en el mundo proviene de los peces

Recibido 13 junio 2007. Aceptado 06 octubre 2007.

'Dirigir correspondencia a J.A.Povh: jayme.peixegen@gmail.com
(FAO, 2004). Sin embargo, poco se conoce sobre su diversidad. Por otra parte, se estima que $20 \%$ de la ictiofauna continental mundial está extinta o amenazada de extinción. Según el Ministerio del Medio Ambiente (2007), cerca de 134 especies de peces de agua dulce están en riesgo de extinción en Brasil actualmente.

Varios son los factores que han llevado a la reducción o al desaparición de poblaciones de peces. Para reducir el impacto de este problema se ha procedido a repoblar ríos. Sin embargo, esta práctica puede aumentar el impacto ambiental y en muchos casos resulta ineficiente. De esta forma, el monitoreo de la diversidad genética de las poblaciones naturales y de lotes de peces mantenidos en piscícolas tiene fundamental importancia para la conservación de las especies. En este contexto los marcadores moleculares pueden ser herramientas útiles. El presente estudio tuvo como objetivo revisar y analizar la importancia del monitoreo genético de programas de repoblamiento de peces mediante marcadores moleculares. 


\section{Impactos en la ictiofauna}

Entre los factores que conducen a la reducción y al desaparición de la ictiofauna (conjunto de especies de peces que existen en una determinada región biogeográfica) se destaca la contaminación de los ríos, la construcción de hidroeléctricas y la sobre pesca (Vrijenhoek, 1998; Agostinho et al., 2003; Hatanaka et al., 2006).

En aguas marinas la pesca industrial ha contribuido considerablemente a la reducción de las poblaciones de peces (Hauser et al., 2002; Bartron y Scribner, 2004; Ayllon et al., 2006). En cambio, en aguas continentales los recursos pesqueros son generalmente explotados por comunidades que viven en inmediaciones de los ríos, lagos y otros reservorios. En muchas regiones, la pesca representa la única fuente de proteína disponible (Hilsdorf et al., 2006). Es así como en ríos brasileños se ha constatado una disminución y desaparición de muchas especies de peces, antes comúnmente capturadas por los pescadores, según datos del Instituto Brasileño del Medio Ambiente y de los Recursos Naturales Renovables (IBAMA).

La construcción de represas hidroeléctricas, actualmente más de 600 en Brasil, es otro factor que en algunos casos explica la reducción de la diversidad de especies en los ríos. Estas interrumpen los movimientos de peces reofílicos (peces que migran para reproducirse), interfieren en el ciclo de vida de los organismos acuáticos y producen alteraciones importantes en los ecosistemas (Agostinho et al., 2003).

Según el IBAMA cualquier entidad que impacte el medio ambiente, debe adoptar métodos y acciones de protección y conservación de los recursos biológicos acuáticos. Entre estas acciones se puede destacar el período de defensa durante la reproducción; el control de la pesca (época, lugar y tamaño mínimo de captura); la prohibición del uso de determinados equipamientos de pesca (ej. dinamita); las cuotas de pesca; la formación de piscícolas y repoblamiento y la construcción de mecanismos de transposición de peces (ej. escaleras, elevadores) (Hilsdorf et al., 2006; Agostinho y Gomes, 2006). Desafortunadamente, a menudo estas estrategias y acciones protectivas para mejorar y conservar los recursos naturales, se han realizado sin el debido respaldo científico (Agostinho et al., 2005).

Los programas de repoblamiento de peces en el Brasil se han practicado por más de tres décadas y cada vez son más comunes, especialmente de especies nativas. En el pasado, hubo mucho interés por la introducción de especies exóticas para aumentar la pesca comercial. Sin embargo, actualmente existe consenso que tal práctica es desaconsejable, pudiendo haber contribuido a la reducción y desaparición de especies autóctonas (Hilsdorf et al., 2006).

En varias regiones de Brasil y estimulado por organismos gubernamentales, las usinas hidroeléctricas y algunas piscícolas comerciales han realizado liberaciones periódicas de peces para poblar o repoblar los ríos. Un ejemplo es el Estado del Paraná en el sur del Brasil, donde se han liberado más de 9,8 millones de peces juveniles en los ríos por medio del programa de "Reposición Pesquera de los ríos Paranaenses" desarrollado por la Secretaría de Estado de Agricultura y Abastecimiento. Este programa, con una inversión de 1,5 millones de dólares, busca recuperar el ambiente por medio de la reposición de las poblaciones de peces y tiene como meta la liberación de aproximadamente 20 millones de alevinos hasta fines de 2007. Entre las últimas liberaciones de peces en los ríos del Paraná, se destacan 230 mil peces juveniles (100.000 Piaractus mesopotamicus, 70.000 Prochilodus lineatus y 60.000 Leporinus elongatus) en el río Paranapanema; 180.000 peces juveniles ( $P$. mesopotamicus y $P$. lineatus) a las márgenes de la "Ilha de Ponciano", en la represa de Xavantes y 200.000 peces juveniles (P. mesopotamicus y P.lineatus) en el río Paranapanema (Anónimo, 2007).

\section{Conservación de la diversidad genética}

La introducción de peces en los ríos es una práctica común en Brasil. Entretanto, los peces migratorios son muy prolíficos lo que limita la utilización de un gran número de reproductores. Esto puede promover un efecto embudo, reduciendo la variabilidad genética (Povh et al., 2006). Por tanto, las introducciones 
de peces de forma irracional, aun cuando realizadas con las mejores intenciones, pueden provocar una reducción de la variabilidad genética. Consecuentemente, esta reducción puede conducir a la pérdida de resistencia a enfermedades y de la capacidad de adaptación a nuevos ambientes (Allendorf y Phelps, 1980; Taniguchi, 2003).

La reproducción de un gran número de peces no garantiza que su descendencia posea alta variabilidad. Es común que en la formación de las parejas de reproductores sean utilizados peces de la propia piscícola. Esto puede favorecer el cruzamiento entre reproductores emparentados genéticamente (endogamia), aumentando la homocigosis y reduciendo la variabilidad genética (Moreira et al., 2003; Povh et al., 2006). La selección casual (no intencionada) de los peces para la reproducción también es un factor que puede reducir la variabilidad genética en las generaciones siguientes (Povh et al., 2006).

La reducción de la variabilidad genética puede promover mayor sensibilidad a las variaciones ambientales y eventualmente puede provocar la extinción de una especie (Guttman y Berg, 1998; Oliveira et al., 2002; Lopera-Barrero et al., 2006). Además, puede afectar el crecimiento y la reproducción (Moreira, 2001; Porta et al., 2006b). Por tanto, la mantención de la variabilidad genética tiene gran importancia para la conservación de las especies (Barroso et al., 2005) y es necesaria para que los individuos enfrenten positivamente las variaciones ambientales y consigan su completo desarrollo (Falconer, 1987; Ryman et al., 1995).

El cruzamiento de peces de la población nativa con peces liberados al ambiente en programas de repoblamiento puede promover la pérdida de importantes genes para la adaptación local (Vasemägi et al., 2005; Sønstebø et al., 2007). Esto se debe a que las poblaciones de una determinada especie tienen un conjunto de genes que les permite adaptarse al medio en que se encuentran. Así, cuando una población local es abastecida con individuos criados en cautiverio, que no son originarios del habitat de la población nativa, se pueden reducir o perder los genes asociados a la supervivencia
(Almeida et al., 2003; Leuzzi et al., 2004). Por lo tanto, para rehabilitar poblaciones reducidas es necesario mantener la variabilidad genética de la población nativa, aspecto que se debe considerar al momento de liberar peces al ambiente a través de programas de repoblamiento.

Es evidente que por el impacto que las especies nativas han sufrido, los lotes de reproductores de las pisciculturas pueden ser una alternativa para la recuperación de las poblaciones de peces. Por lo tanto, el repoblamiento de peces en los ríos permite promover la conservación de los recursos genéticos especialmente cuando existe riesgo de extinción (Koljonen et al., 2002; Barroso et al., 2005).

En consecuencia, cualquier acción para recuperar el ambiente debe considerar métodos científicos de monitoreo. Con este propósito, los marcadores moleculares son una de las metodologías más adecuadas (Povh et al., 2006). Estos se pueden utilizar para la caracterización genética de las poblaciones nativas de peces y lotes de peces, para identificar especies y para estudiar los efectos de las variaciones ambientales sobre la variabilidad genética (Ryman y Utter, 1987).

\section{Marcadores moleculares}

Los marcadores genéticos son instrumentos importantes para el estudio de poblaciones y lotes de peces. El desarrollo de metodologías moleculares ha permitido el análisis del genoma y de las variaciones existentes, tanto en regiones que codifican productos génicos, como en aquellas cuyas funciones aún permanecen desconocidas (Regitano, 2001a).

El monitoreo genético es lo ideal en un programa de reproducción cuya finalidad es la conservación genética (ej. repoblamiento). Para esto, los marcadores moleculares son una herramienta realista y útil para la investigación y el monitoreo de la condición genética en poblaciones nativas y en lotes mantenidos en cautiverio (Alam y Islam, 2005).

Entre los marcadores moleculares utilizados para analizar la diversidad genética de peces, 
se destacan los marcadores RAPD (Random Amplified Polymorphic DNA) y microsatélite, ambos relacionados a la técnica de PCR (Polymerase Chain Reaction).

\section{PCR (Polymerase Chain Reaction)}

La biología molecular se desarrolló de una forma explosiva después del descubrimiento de la estructura del ADN, en 1953 por Watson y Crick. Desde entonces, han surgido diversas técnicas de biología molecular posibilitando la detección de polimorfismo al nivel del ADN. Según Rieseberg (1996), estas técnicas pueden ser útiles en estudios de genética de poblaciones, sistemática y ecología de diversos organismos.

Una gran contribución de la biología molecular fue la técnica PCR o reacción en cadena de la polimerasa desarrollada por Mullis en 1983. Esta técnica consiste en la replicación de ADN in vitro catalizada por la enzima Taq ADN polimerasa y la alternación de ciclos de temperatura. Esta enzima cataliza la síntesis de una cadena de ADN complementaria a la cadena molde, partiendo de las extremidades $3^{\prime} \mathrm{OH}$ de oligo-nucleótidos sintéticos (partidores) suministrados a la reacción. Los partidores deben ser complementarios a las extremidades de la región del ADN que se desea amplificar, por lo que es necesario el conocimiento previo de la secuencia de nucleótidos de las extremidades de esta región (Regitano, 2001a).

\section{RAPD (Random Amplified Polymorphic DNA)}

Debido a la alta especificidad y sensibilidad, el PCR se transformó en la principal técnica de diagnóstico molecular y en herramienta esencial para los más diversos campos de la investigación genética. Entretanto, la aplicación de los marcadores moleculares se hizo más accesible con el desarrollo del marcador RAPD, propuesto por dos grupos de investigadores independientes, Williams et al. (1990) y Welsh y McClelland (1990). Esta técnica ha sido ampliamente utilizada debido a la rapidez, accesibilidad y alto polimorfismo que permite detectar. Además, sólo requiere de pequeñas cantidades de ADN para su amplificación y no es necesario conocer previamente el genoma de la especie (Bártfai, 2003).
El marcador RAPD permite analizar el ADN mediante el uso de partidores únicos de secuencia simple y arbitraria, normalmente de diez pares de bases. Un partidor arbitrario pequeño puede dirigir la síntesis de varios segmentos de ADN de manera simultánea en diversos puntos del genoma. Las variaciones de tamaño en los productos de amplificación pueden visualizarse como bandas en geles de agarosa, generándose considerable información respecto de la variabilidad de los nucleótidos en el genoma (Borowsky, 2001).

La amplificación de un determinado segmento RAPD requiere de dos secuencias complementarias, uno para cada una de las hebras de la doble hélice. El polimorfismo de los productos de amplificación se debe a diferencias en el ADN, como modificación, eliminación e inserción de nucleótidos, en los sitios de acoplamiento de los partidores o en la secuencia de ADN que los separa. Estos cambios en el ADN pueden prevenir la amplificación por falta de complementariedad en los sitios de unión de los partidores, o por una distancia demasiado grande entre los sitios de acoplamiento (Ferreira y Grattapaglia, 1998).

El número de bandas obtenidas por un marcador RAPD es (virtualmente) ilimitado. Varios partidores pueden ser utilizados en forma simultánea y las secuencias de los segmentos amplificados varían entre ADN de copia única y ADN altamente repetido, lo que proporciona un aumento en la variación genética detectada (Oliveira et al., 2002).

A pesar del menor costo y menor número de etapas y tiempo para la obtención de resultados en comparación con otras técnicas moleculares, el marcador RAPD tiene algunas desventajas (Milach, 1998). Entre las desventajas están las siguientes: 1. Presenta característica dominante lo que dificulta asumir homología entre dos segmentos amplificados de igual tamaño (Lynch y Milligan, 1994), 2. Sensibilidad a pequeñas modificaciones en la concentración de los componentes de la reacción, pudiendo producir alteraciones en el patrón de los marcadores y 3. Bajo grado de reproducibilidad de los resultados (Pérez et al., 1998). 
Generalmente, la reproducibilidad del marcador RAPDdepende del ADNy delaconcentración de magnesio usado en la reacción de amplificación (MacPherson et al., 1993). Entretanto, una mayor precisión de esta técnica se puede obtener ajustando el criterio de la selección de los segmentos (bandas) amplificados. Por ejemplo, la selección de bandas asociadas a características heredables de tipo mendelianas o de las que presentan repetición en dos o más amplificaciones independientes con el mismo partidor.

El marcador RAPD es una herramienta potencial para monitorear la variación genética de poblaciones y lotes de peces. Además, debido a su simplicidad y bajo costo se puede emplear como técnica complementaria en el manejo reproductivo con el objetivo de minimizar la pérdida de variabilidad genética de la progenie.

\section{Marcador microsatélite}

En los genomas de los eucariontes existe gran cantidad de ADN repetitivo, clasificado según su complejidad y número de nucleótidos. Las secuencias microsatélites están entre estos tipos de elementos. Su alto contenido polimórfico es una importante característica para el estudio de individuos dentro y entre poblaciones. Del mismo modo, son útiles en estudios filogenéticos y en la construcción de mapas genéticos de alta precisión. Por ejemplo, se han utilizado para la identificación de loci asociados a enfermedades y a características cuantitativas como tamaño y peso (Yan et al., 2005).

Los microsatélites son secuencias simples repetidas (SSR, Simple Sequence Repeats), compuestas por la repetición de grupos de uno a cuatro nucleótidos. Son estructuras muy frecuentes en los genomas y se distribuyen aleatoriamente. Esto permite una amplia cobertura del genoma eucarionte (Ferreira y Grattapaglia, 1998). Recientemente, se ha reportado que el número de nucleótidos de las repeticiones puede variar entre uno y ocho (Alam y Islam, 2005).

Cada bloque de repeticiones es generalmente menor que 100 pares de nucleótidos. De la misma forma que otras regiones repetitivas del genoma, la variación del número de repeticiones en cada locus es, probablemente, resultado de errores en la lectura de la ADN polimerasa durante la replicación del ácido nucleico (Regitano, 2001a).

Las características de este tipo de marcador lo tornan ideal para el mapeo genético y físico de genomas, para la identificación y discriminación de genotipos y para estudios de genética poblacional. Desde el punto de vista de la biología molecular, los SSR son los marcadores que tienen el más elevado contenido de información de polimorfismo por locus, siendo útiles en la detección de altos niveles de variación y de alelos raros (Alam y Islam, 2005; Ferreira y Grattapaglia, 1998).

Cuando las secuencias repetitivas de ADN están localizadas en regiones de copia única pueden ser analizadas por la técnica de PCR, con el empleo de partidores específicos, complementarios a las secuencias conservadas que los rodean (Regitano, 2001b). La separación de los productos de PCR se debe realizar por un proceso de alta definición, usualmente electroforesis en gel de poliacrilamida desnaturalizante $\mathrm{o}$ en secuenciador con programas específicos para detectar las variaciones microsatélites, las cuales pueden ser de apenas uno o dos pares de bases.

El uso de partidores complementarios a secuencias de copia única, permite obtener marcadores uni-locales, altamente polimórficos y de herencia co-dominante (Regitano, 2001a). Según Ferreira y Grattapaglia (1998), las características del método permiten que toda y cualquier población segregante se pueda utilizar como población de referencia para estudios de ligamiento y mapeo genético.

Algunos microsatélites tienen un gran número de alelos ( $>20$ alelos por locus), lo que los torna útiles para aplicaciones como identificación de paternidad en poblaciones complejas. En cambio, microsatélites con un número menor de alelos son más apropiados para estudios de genética poblacional y filogenia. En genomas animales, la constatación de que ocurre conservación de sitios genéticos en especies 
relacionadas facilita, en algunos casos, la transferencia de marcadores entre especies o mismos géneros, mediante el uso de partidores heterólogos (Mia et al., 2005).

El desarrollo de estos marcadores se puede realizar por análisis de secuencias contenidas en bancos de datos, a través de la localización de los microsatélites y del diseño de partidores para la región que delimita la repetición. Esta estrategia está limitada por la cantidad de información catalogada en los bancos de datos. La selección de fragmentos contenidos en una biblioteca genómica es otra estrategia muy utilizada. Otra posibilidad es a través de la clonación por hibridización de colonias de microorganismos específicos para esta finalidad (Regitano, 2001a).

En las últimas décadas, los análisis por microsatélite emergieron debido a su gran sensibilidad para detectar variaciones genéticas dentro y entre poblaciones. Estos marcadores son sensibles indicadores de la homocigosis resultante de cruzamientos endogámicos $\mathrm{y}$, de esta forma, aplicables a la distinción de pequeñas diferenciaciones poblacionales. Diversos estudios demuestran que este tipo de marcador es ideal para el estudio de la diversidad genética en organismos acuáticos (Yan et al., 2005). Los microsatélites se consideran los marcadores más eficientes para revelar altos niveles de variación alélica y permiten frecuentemente detectar diferencias entre poblaciones íntimamente relacionadas. Es así como, el polimorfismo obtenido por marcadores microsatélite se ha convertido en una poderosa herramienta para el manejo de lotes en acuicultura (Alam y Islam, 2005), para el análisis poblacional y para la conservación de la biodiversidad (RomanaEguia et al., 2004).

\section{Monitoreo de la diversidad genética de poblaciones nativas de peces}

La variabilidad genética de muchas poblaciones de peces es muy variable, dependiendo de la especie, de la ubicación del río y de las presiones existentes en cada ambiente. Por ejemplo, con el uso de RAPD, en las poblaciones de Astyanax scabripinnis del río Cambé (Londrina, Paraná), considerado un río contaminado, se encontró que un 63,5 a $64,8 \%$ de polimorfismo pudo explicar la tolerancia de esta especie para las actuales condiciones físico-químicas del río (Sofia et al., 2006). Después de analizar con el marcador RAPD la variabilidad genética de poblaciones de Pimelodus maculatus de los ríos Tietê y Paranapanema, se constató valores variables de polimorfismo entre las poblaciones $(51,94$ a 61,51\%) (Almeida et al., 2003). Trabajando con el mismo marcador, Leuzzi et al. (2004) encontraron valores inferiores de variabilidad genética en la población ubicada en la parte inferior $(42,64 \%)$ en relación a las poblaciones de la parte media y alta del río Paranapanema $(75,0 \%)$.

Además de la variabilidad, la diferenciación genética existente entre las poblaciones de un río es otro aspecto importante (Almeida et al., 2003; Leuzzi et al., 2004). Cuando existe una alta diferenciación genética entre los peces liberados de programas de repoblamiento, y entre las poblaciones nativas, como resultado del repoblamiento se pueden perder importantes genes asociados con factores de adaptación a las condiciones ambientales locales.

En la definición de Wright (1978), se pueden clasificar las poblaciones en cuatro niveles de diferenciación genética $\left(F_{\mathrm{ST}}\right)$ : baja $(0,00$ a 0,05$)$, moderada $(0,05$ a 0,15$)$, alta $(0,15$ a $0,25)$ y elevada $(>0,25)$. Sobre la base de esta definición, Leuzzi et al. (2004) constataron una moderada a alta diferenciación genética $(0,0895$ a 0,2813$)$ entre poblaciones de $A$. altiparanae del río Paranapanema. Hubo un alto número de emigrantes por generación $(\mathrm{Nm}$ $=2,54$ ) entre las poblaciones del reservorio de Capivara (medio Paranapanema) y Jurumirim (alto Paranapanema). Estos resultados fueron inesperados, pues antes que la primera represa hidroeléctrica fuera construida en dicho río, existía una barrera geográfica natural (cascada de Salto Grande). Por lo tanto, posiblemente los dos reservorios hayan sido reabastecidos con alevines de A. altiparanae en programas de repoblamiento. Igualmente, Almeida et al. (2003) encontraron una diferenciación genética media entre las poblaciones del río Tietê $(0,0716$ a 0,1007$)$ y una alta diferenciación entre las poblaciones del río Paranapanema $(0,1870$ a $0,2103)$. Probablemente esto se debe a un mayor 
flujo genético entre las poblaciones del primer río (número de emigrantes por generación, $\mathrm{Nm}$ $=4,333$ a 6,481) en relación al segundo río $(\mathrm{Nm}$ $=1,878$ a 2,173).

Además de la interferencia del hombre en el ambiente, con la construcción de represas hidroeléctricas, son varios los factores que pueden establecer un mayor o menor flujo genético entre las poblaciones. Las diferencias genéticas entre poblaciones, promovidas por la ausencia parcial o total de flujo genético, pueden ocurrir debido a barreras naturales del río o también debido a diferentes migraciones reproductivas. Un ejemplo de este último caso lo observaron Wasko y Galetti Jr. (2002), constatando a través del marcador RAPD que los peces (Brycon lundii) colectados de diferentes localidades del río São Francisco presentan simpatria, con la existencia de por lo menos dos poblaciones distintas. Probablemente, esto se debe a migraciones reproductivas diferenciadas. A la misma conclusión llegaron Hatanaka y Galetti Jr. (2003) y Hatanaka et al. (2006) estudiando Prochilodus marggravii de diferentes localidades del río São Francisco, con los marcadores RAPD y microsatélite, respectivamente.

En consecuencia, los estudios poblacionales de peces son importantes para el conocimiento de la diversidad genética, y pueden contribuir a promover la conservación y el aumento de los recursos explotables (Ortega-Villaizán Romo et al., 2006).

\section{Monitoreo de la diversidad genética de lotes de peces mantenidos en cautiverio}

El monitoreo de la variabilidad genética y de la endogamia en las piscícolas es importante para la conservación de la capacidad de adaptación de una especie (Saura et al., 2006). Según Wang et al. (2002), un 10\% de aumento en la endogamia puede resultar en una reducción de la capacidad de supervivencia en alrededor de 3 a 15\%. Esto fue constatado por Shikano y Taniguchi (2002ab), los cuales observaron una correlación negativa entre la endogamia, la supervivencia y también con la tolerancia a la salinidad en Poecilia reticulada. Cena et al. (2006), también constataron una correlación negativa entre la endogamia y el crecimiento en Sander vitreus.

Después de comparar peces de lotes en cautiverio y de poblaciones nativas, Porta et al. (2006), Saura et al. (2006) y Neville et al. (2007), constataron una variabilidad genética similar entre estos, en las especies Solea senegalensis, Salmo salar y Oncorhynchus tshawytscha, respectivamente. Sin embargo, los resultados obtenidos con Sparus aurata (Alarcón et al., 2004), Haliotis discus hannai (Li et al., 2004); Sekino et al. (2002), Paralichthys olivaceus (Hara y Sekino, 2003; Kang et al., 2006) y Verasper variegatus (Ortega-Villaizán Romo et al., 2005) demuestran lo contrario.

Los principales motivos para la reducción de la variabilidad genética de lotes en cautiverio se atribuye a la utilización de pocos reproductores y al cruzamiento de individuos emparentados (Wasko et al., 2004). Estos autores constaron que el empleo de apenas seis a ocho reproductores porgeneración y el cruzamiento entre individuos emparentados, fueron los responsables de una disminución de la variabilidad genética de los lotes de reproductores de Brycon cephalus del Centro Nacional de Pesquisa de Peces Tropicales (CEPTA) en relación a una población nativa del río Amazonas.

El manejo reproductivo puede ocasionar, en apenas una generación, una gran pérdida de la variabilidad genética, como se concluye en el trabajo de Porta et al. (2006b). Estos autores, estudiando Solea senegalensis constataron una gran reducción de la variabilidad genética de los reproductores de la primera generación con respecto a dos generaciones posteriores, en relación con el número de alelos microsatélites (aproximadamente 50\%).

Otro factor responsable de la reducción de la variabilidad genética es la selección no intencional (Povh et al., 2006). Es así como la selección por tamaño para reducir el canibalismo, principalmente en las especies carnívoras, también tiende a proporcionar una gran reducción de la variabilidad genética, como se observó en Lates calcarifer (Frost et al., 2006). Según estos autores la selección por tamaño para reducir el canibalismo proporcionó 
una reducción de la variabilidad genética. Además hubo una alteración en la composición de las familias, inclusive con algunos machos dejando de contribuir con la progenie.

Ortega-Villaizán Romo, et al. (2006) observaron alteraciones en la composición de las familias antes y después de la liberación en Verasper variegatus. Sin embargo, no observaron diferencias entre las recapturas realizadas en el ambiente. Por otra parte, dependiendo del efecto fundador del lote y del manejo reproductivo, la composición de las familias puede no ser alterada antes y después de la liberación en el ambiente. Esta situación se observó con Paralichthys olivaceus (Sekino et al., 2005).

Como la pérdida de la variabilidad genética es naturalmente irreversible, pudiendo ser recuperada sólo con la introducción de un nuevo material genético, es importante la conservación de la variabilidad genética en los lotes de peces mantenidos en cautiverio (Yokota et al., 2003; Sekino et al., 2004). Así, el monitoreo de los lotes es un recurso que se puede emplear con este propósito (Lopera-Barrero, 2005; Gomes, 2007). Se ha obtenido alta variabilidad genética de los lotes de Leporinus elongatus y de Brycon orbignyanus, a través del monitoreo realizado con un marcador RAPD (Lopera-Barrero, 2005; Gomes, 2007).

\section{Conclusiones}

El monitoreo de la diversidad genética de las poblaciones nativas y de los lotes mantenidos en cautiverio de peces es importante para la conservación de las especies. En este sentido, los marcadores moleculares (ej., RAPD y microsatélites) pueden ser eficientemente utilizados para cumplir con este propósito, especialmente en programas de repoblamiento de peces en los ríos.

\section{Resumen}

Las poblaciones de peces nativos están disminuyendo debido a varios factores que impactan en el ambiente. Como forma de abordar este problema, se han realizado varias acciones como por, ejemplo, el repoblamiento.
Sin embargo, estas acciones se realizan sin ningún respaldo científico. Esto puede, además de no ser eficiente, provocar una pérdida de la diversidad genética en las poblaciones, pudiendo ocasionar impactos irreversibles en las próximas generaciones. Por esta razón, el empleo de marcadores moleculares, que permitan monitorear genéticamente las poblaciones parece fundamental para lograr la conservación de la ictiofauna.

Palabras clave: Conservación genética, ictiofauna, microsatélite, pez, RAPD, variabilidad genética.

\section{Literatura citada}

Agostinho, A.A. y L.C. Gomes. 2006. O manejo da pesca em reservatórios da bacia do alto rio Paraná: avaliação e perspectivas. Pages 23-55. In: Nogueira, M.G., R. Henry and A. Jorcin (eds.). Ecologia de reservatórios: impactos potenciais, ações de manejo e sistemas em cascatas. RiMA, São Carlos, Brasil.

Agostinho, A.A., L.C. Gomes y H.I. Suzuki. 2003. Migratory fish of upper Paraná river basin, Brazil. Pages 19-99. In: Carolsfed, J., B. Harvey, A. Baer and C. Ross (eds.). Migratory fishes of South America: Biology, Social Importance and Conservation Status. World Fisheries Trust, Victoria, EE.UU.

Agostinho, A.A., S.M. Thomaz. y L.C. Gomes. 2005. Conservação da biodiversidade em águas continentais do Brasil. Megadiversidade 1:7078.

Alam, M.S. y M.S. Islam. 2005. Population genetic structure of Catla catla (Hamilton) revealed by microsatellite DNA markers. Aquaculture 246:151-160.

Alarcón, J.A., A. Magoula, T. Georgakopoulo, E. Zorros y M.C. Alvarez. 2004. Genetic comparison of wild and cultivated European populations of the gilthead sea bream (Sparus aurata). Aquaculture 230:65-80.

Allendorf, F.W. y S.R. Phelps. 1980. Loss of genetic variation in a hatchery stock of cutthroat trout. Transactions of the American Fisheries Society 109:537-543.

Almeida, F.S., L.M.K. Sodré y E.P.B. Contel. 2003. Population structure analysis of Pimelodus maculatus (Pisces, Siluriformes) from the Tietê and Paranapanema Rivers (Brazil). Genetics and Molecular Biology 26:301-305.

Anónimo. 2007. Agência Estadual de Notícias. www.agenciadenoticias.pr.gov.br (Consultado: enero de 2007). 
Ayllon, F., J.L. Martinez y E. Garcia-Vazquez. 2006. Loss of regional population structure in Atlantic salmon, Salmo salar L., following stocking. ICES Journal of Marine Science 63:1269-1273.

Barroso, R.M, A.W.S. Hilsdorf, H.L.M. Moreira, P.H. Cabello y Y. Traub-Cseko. 2005. Genetic diversity of wild and cultured populations of Brycon opalinus (Cuvier, 1819) (Characiforme, Characidae, Bryconiae) using microsatellites. Aquaculture 247:51-65.

Bártfai, R., S. Egedi, G.H. Yue, B. Kovács, B. Urbányi, G. Tamás, L. Horváth y L. Orbán. 2003. Genetic analysis of two common carp broodstocks by RAPD and microsatellite markers. Aquaculture 219:157-167.

Bartron, M.L. y K.T. Scribner. 2004. Temporal comparisons of genetic diversity in Lake Michigan steelhead, Oncorhynchus mykiss, populations:effectsof hatcherysupplementation. Environmental Biology of Fishes 69:395-407.

Borowsky, R.L. 2001. Estimating nucleotide diversity from Random Amplified Polymorphic DNA and Amplified Fragment Length Polymorphism data. Molecular Phylogenetics and Evolution 18:143-148.

Buckup, P.A. y N.A. Menezes. 2003. Catálogo dos peixes marinhos e de água doce do Brasil. www. mnrj.ufrj.br/catalogo (Consultado: noviembre de 2006).

Cena, C.J., G.E. Morgan, M.D. Malette y D.D. Heath. 2006. Inbreeding, outbreeding and environmental effects on genetic diversity in 46 walleye (Sander vitreus) populations. Molecular Ecology 15:303-320.

Falconer, D.S. 1987. Introdução a genética quantitativa. UFV, Viçosa, Brasil. 279 pp.

FAO. 2004. State of World Fisheries and Aquaculture. Roma: FAO Fisheries Department. 153 pp.

Ferreira, M.E. y D. Grattapaglia. 1998. Introdução ao uso de marcadores moleculares em análise genética. EMBRAPA, Brasilia. 220 pp.

Frost, L.A., B.S. Evans y D.R. Jerry. 2006. Loss of genetic diversity due to hatchery culture practices in barramundi (Lates calcarifer). Aquaculture 261:1056-1064.

Gomes, P.C. 2007. Diversidade genética de três populações de piapara (Leporinus elongatus), utilizandomarcadores moleculares. Dissertação, Mestrado em Zootecnia, Universidade Estadual de Maringá, Maringá, Brasil. 75 p.

Guttman, S.I. y D. Berg. 1998. Changes in the genetic diversity of aquatic organisms in the great lakes: causes and consequences. Setac News. p. 23-24.

Hara, M. y M. Sekino. 2003. Efficient detection of parentage in a cultured Japanese flounder Paralichthys olivaceus using microsatellite DNA marker. Aquaculture 217:107-114.
Hatanaka, T. y P.M. Galetti Jr. 2003. RAPD markers indicate the occurrence of structured populations in a migratory freshwater fish species. Genetics and Molecular Biology 26:19-25.

Hatanaka, T., F. Henrique-Silva y P.M. Galetti Jr. 2006. Population substructuring in a migratory freshwater fish Prochilodus argenteus (Characiformes, Prochilodontidae) from the São Francisco River. Genetica 126:513-517.

Hauser, L., G.J. Adcock, P.J. Smith, J.H. Ramírez y G.R. Carvalho. 2002. Loss of microsatellite diversity and low effective population size in an overexploited population of New Zealand snapper (Pagrus auratus). PNAS 99:1174211747.

Hilsdorf, A.W.S., E.K. Resende y D.K.S. Marques. 2006. Genética e Conservação de Estoques Pesqueiros de Águas Continentais no Brasil: Situação Atual e Perspectivas. Corumbá: Embrapa Pantanal. pp. 44.

Kang, J.H., J.K. Noh, J.H. Kim, J.H. Lee, H.C. Kim, K.K. Kim, B.S. Kim y W.J Lee. 2006. Genetic relationship between broodstocks of olive flounder, Paralichthys olivaceus (Temminck and Schlegel) using microsatellite markers. Aquaculture Research 37:701-707.

Koljonen, M.L., J. Tähtinen, M. Säisä y J. Koskiniemi. 2002. Maintenance of genetic diversity of Atlantic salmon (Salmo salar) by captive breeding programmes and the geographic distribution of microsatellite variation. Aquaculture 212:69-92.

Leuzzi, M.S.P., F.S. Almeida, M.L. Orsi y M.L.K. Sodré. 2004. Analysis by RAPD of the genetic structure of Astyanax altiparanae (Pisces, Characiformes) in reservoirs of the River Paranapanema. Genetics and Molecular Biology 27:355-362.

Li, Q., C. Park, T. Endo y A. Kijima. 2004. Loss of genetic variation at microsatellite loci in hatchery strains of the Pacific abalone (Haliotis discus hannai). Aquaculture 235:207-222.

Lopera-Barrero, N.M. 2005. Diversidade genética de populações de piracanjuba (Brycon orbignyanus), com a técnica de RAPD. Dissertação, Mestrado em Zootecnia, Universidade Estadual de Maringá, Maringá, Brasil, 45 p.

Lopera-Barrero, N.M., R.P. Ribeiro, R.N. Sirol, J.A. Povh, P.C. Gomes, L.Vargas y D.P. Streit Jr. 2006. Genetic diversity in piracanjuba populations (Brycon orbignyanus) with the RAPD (Random Amplified Polimorphic DNA) markers. Journal Animal Science 84:170-170.

Lynch, M. y B.G. Milligan. 1994. Analysis of population genetic structure with RAPD markers. Molecular Ecology 3:91-99.

Macpherson, J.M., P.E. Eckstein, G.J. Scoles y 
A.A. Gajaghar. 1993. Variability of the random amplified polymorphic DNA assay among thermal cycles, and effects of primer and DNA concetration. Molecular and Cellular Probes 7:293-299.

Mia, M.Y., J.B. Taggart, A.E. Gilmour, A.A. Gheyas, T.K. Das, H.M. Kohinoora, M.A. Rahman, M.A. Sattar, M.G. Hussain, M.A. Mazid, D.J. Penman y B.J. Mcandrew. 2005. Detection of hybridization between Chinese carp species (Hypophthalmichthys molitrix and Aristichthys nobilis) in hatchery broodstock in Bangladesh, using DNA microsatellite loci. Aquaculture 247:267-273.

Milach, S. 1998. Principais tipos de marcadores moleculares e suas características. Pages 17-28. In: Milach, S.C.K. (ed.). Marcadores moleculares em plantas. UFRGS, Porto Alegre, Brasil.

Moreira, H.L.M. 2001. Genética e melhoramento de peixes. Pages 135-147. In: Moreira, H.L.M., L. Vargas, R.P. Ribeiro and S. Zimmermann (eds.). Fundamentos da moderna aqüicultura. ULBRA, Canoas, Brasil.

Moreira, H.L.M., S.Zimmermann, R.P.Ribeiro, R.G. Bastos, L.D. Vargas y J.A. Povh. 2003. The use of RAPD (Random Amplified Polymorphism DNA) for genetic monitoring in breeding programs of tilapia. Page 460. In: World Aquaculture, Salvador, Brasil (Abstract).

Neville, H., D. Isaak, R. Thurow, J. Dunham y B. Rieman. 2007. Microsatellite variation reveals weak genetic structure and retention of genetic variability in threatened Chinook salmon (Oncorhynchus tshawytscha) within a Snake River watershed. Conservation Genetics 8:133147.

Oliveira, A.V., J.A. Prioli, S.M.A.P. Prioli, C.S. Pavanelli, H.F. Júlio Jr. y R.S. Panarari. 2002. Diversity and genetic distance in populations of Steindachnerina in the Upper Paraná river floodplain. Genetica 115:259-257.

Ortega-Villaizán Romo, M.M., M. Aritaki y N. Taniguchi. 2006. Pedigree analysis of recaptured fish in the stock enhancement program of spotted halibut Verasper variegates. Fisheries Science 72:48-52.

Ortega-Villaizán Romo, M.M., S. Suzuki, M. Ikeda, M. Nakajima y N. Taniguchi. 2005. Monitoring of the genetic variability of the hatchery and recaptured fish in the stock enhancement program of the rare species barfin flounder Verasper moseri. Fisheries Science 71:11201130.

Pérez, T., J. Albornoz y A. Domínguez. 1998. An evaluation of RAPD fragment reproducibility and nature. Molecular Ecology 7:1347-1357.

Porta, J., J.M. Porta, G. Matínez-Rodríguez y M.C.
Alvarez. 2006a. Development of a microsatellite multiplex PCR for Senegalese sole (Solea senegalensis) and its application to broodstock management. Aquaculture 256:159-166.

Porta, J., J.M. Porta, G. Matínez-Rodríguez y M.C. Alvarez. 2006b. Genetic structure and genetic relatedness of a hatchery stock of Senegal sole (Solea senegalensis) inferred by microsatellites. Aquaculture 251:46-55.

Povh, J.A., R.P. Ribeiro, R.N. Sirol, C.A. Mangolin, E. Gasparino, N.M. Lopera-Barrero, P.C. Gomes, D.P. Streit Jr. y L. Vargas. 2006. Importância do monitoramento genético pela utilização de marcadores moleculares na piscicultura. CD-ROM. In: AquaCiência, Bento Gonçalves, Brasil (Resumo).

Regitano, L.C.A. 2001a. Introdução à análise de marcadores moleculares. Pages 25-39. In: Regitano, L.C.A. and L.L. Coutinho (eds.). Biologia molecular aplicada à produção animal. EMBRAPA, Brasília, Brasil.

Regitano, L.C.A. 2001b. Protocolo de Análise de Marcadores Microssatélites. Pages 195-215. In: Regitano, L.C.A. and L.L. Coutinho (eds.). Biologia Molecular Aplicada à Produção Animal. EMBRAPA, Brasília, Brasil.

Reis, R.E., S.O. Kullander y C.J. Ferrari Jr. 2003. Check list of the freshwater fishes of South and Central America. EDPUCRS, Porto Alegre, Brasil. 729 pp.

Rieseberg, L.H. 1996. Homology among RAPD fragments in interspecific comparisons. Molecular Ecology 5:99-105.

Romana-Eguia, M.R.R., M. Ikeda, Z.U. Basiao y N. Taniguchi. 2004. Genetic diversity in farmed Asian Nile and red hybrid tilápia stocks evaluated from microsatellite and mitochondrial DNA analysis. Aquaculture 236:131-150.

Ryman, N. y F. Utter. 1987. Population Genetics and Fishery Management. University of Washington Press, Seattle, USA.

Ryman, N., F. Utter y L. Laikre. 1995. Protection of intraspecic biodiversity of exploited fishes. Reviews Fish Biology and Fisheries 5:417-446.

Saura, M., P. Caballero, A. Caballero y P. Morán. 2006. Genetic variation in restored Atlantic salmon (Salmo salar L.) populations in the Ulla and Lérez rivers, Galicia, Spain. ICES Journal of Marine Science 63:1290-1296.

Schaefer, S.A. 1998. Conflict and resolution: impact of new taxa on phylogenetic studies of the neotropical cascudinhos (Siluroidei: Loricariidae).Pages 375-400In:L.R. Malabarba, R.E. Reis, R.P. Vari, Z.M.S. Lucena and C.A.S. Lucena (eds.). Phylogeny and Classification of Neotropical Fishes. EDIPUCRS, Porto Alegre, Brasil.

Sekino, M., K. Saitoh, T. Yamada, M. Hara y Y. 
Yamashita. 2005. Genetic tagging of stocking Japanese flounder (Paralichthys olivaceus) based on polymorphic DNA markers. Aquaculture 244:49-61.

Sekino, M., M. Hara y N. Taniguchi. 2002. Loss of microsatellite and mitochondrial DNA variation in hatchery strains of Japanese flounder Paralichthys olivaceus. Aquaculture 213:101-122.

Sekino, M., T. Sugaya, M. Hara y N. Taniguchi 2004. Relatedness inferred from microsatellite genotypes as a tool for broodstock management of Japanese flounder Paralichthys olivaceus. Aquaculture 233:163-172.

Shikano, T. y N. Taniguchi. 2002a. Heterosis for neonatal survival in the guppy. Journal of Fish Biology 60:715-725.

Shikano, T. y N. Taniguchi. 2002b. Using microsatellite and RAPD markers to estimate the amount of heterosis in various strain combinations in the guppy (Poecilia reticulate) as a fish model. Aquaculture 204:271-281.

Sofia, S.H., C.R.M. Silva, B.A. Galindo, F.S. Almeida, L.M.K. Sodré y C.B.R. Martinez. 2006. Population genetic structure of Astyanax scabripinnis (Teleostei, Characidae) from an urban stream. Hydrobiologia 553:245-254.

Sønstebø, J.H., R. Borgstrøm y M. Heun. 2007. Genetic structure of brown trout (Salmo trutta L.) from the Hardangervidda mountain plateau (Norway) analyzed by microsatellite DNA: a basis for conservation guidelines. Conservation Genetics 8:33-44.

Taniguchi, N. 2003. Genetic factors in broodstock management for seed production. Reviews Fish Biology and Fisheries 13:175-185.

Vasemägi, A., R. Cross, T. Paaver, M.L. Koljonen y J. Nilsson. 2005. Extensive immigration from compensatory hatchery releases into wild Atlantic salmon population in the Baltic sea: spatio-temporal analysis over 18 years. Heredity 95:76-83.

Vrijenhoek, R.C. 1998. Conservation genetics of freshwater fish. Journal of Fish Biology 53: (Suppl. A):394-412.

Wang, S., J.J. Hard y F. Utter. 2002. Salmonid inbreeding: a review. Reviews in Fisheries Biology and Fisheries 11:301-319.

Wasko, A.P. y P.M. Galetti Jr. 2002. RAPD analysis in the Neotropical fish Brycon lundii: genetic diversity and its implications for the conservation of the species. Hydrobiologia 474:131-137.

Wasko, A.P., C. Martins, C. Oliveira, J.A. Senhorini y F. Foresti 2004. Genetic monitoring of the Amazonian fish matrinchã (Brycon cephalus) using RAPD markers: insights into supportive breeding and conservation programmes. Journal of Applied Ichthyology 20:48-52.

Welsh, J. y M. Mcclelland. 1990. Fingerprinting genomes using PCR with arbitrary primers. Nucleic Acids Research 18:7213-7218.

Williams, J.G.K., A.R. Kubelik, K.J. Livak, J.A. Rafalski y S.V. Tingey. 1990. DNA polymorphisms amplified by arbitrary primers are useful as genetic markers. Nucleic Acids Research 18:6531-6535.

Wright, S. 1978. Evolution and Genetics of Populations. University of Chicago Press, Chicago, USA. 511 pp.

Yan, J., S., Liu, Y. Sun, C. Zhang, K. Luo y Y. Liu. 2005. RAPD and microsatellite analysis of diploid gynogens from allotetraploid hybrids of red crucian carp (Carassius auratus) X common carp (Cyprinus carpio). Aquaculture 243:49-60.

Yokota, M., Y. Harada y M. Iizuka. 2003. Genetic drift in a hatchery and the maintenance of genetic diversity in hatchery-wild systems. Fisheries Science 69:101-109. 